\title{
La Recreación física en el tiempo libre de los estudiantes de educación básica superior
}

\begin{abstract}
(c) (1) () (2)
\end{abstract}
Physical recreation in free time of higher basic education students

Vicente Flores Bryan Efrén. ${ }^{1}$, González Córdova Carlos Eduardo. ${ }^{2}$ \& Sandoval Jaramillo María Lorena. ${ }^{3}$

Recibido: 27-06-2021 / Revisado: 13-07-2021 /Aceptado: 25-07-2021/ Publicado: 05-08-2021

\begin{abstract}
DOI: $\underline{\text { https://doi.org/10.33262/concienciadigital.v4i3.1.1897 }}$

This article is based on physical recreation together with the free time of the students of Higher Basic Education of the Theodore Wilbur Anderson Educational Unit to be able to know the use they give to their free time, and thus also know if in that time they do or they know about physical recreation, because in this age of online classes, many adolescents have given more time and use to electronic devices, which has caused them to neglect to carry out physical activities in the little or a lot of free time they have, That is why the general objective of this study is to analyze the appropriate use of students' free time in order to propose planning based on what physical recreation is so that students make better use of their free time, therefore which, an extensive theoretical and bibliographic review of various authors was carried out, this study was carried out through a descriptive investigation, to be able to analyze the The data collected was used a questionnaire carried out in Google Forms with 7 questions which gave the following results, the 17-year-old students of the Theodore Wilbur Anderson Educational Unit are the most interested in doing physical activities in their free time, in second place they are

\footnotetext{
${ }^{1}$ Universidad de las Fuerzas Armadas. (ESPE), Carrera: Pedagogía de la Actividad Física y Deporte bevicente@espe.edu.ec ORCID ID: https://orcid.org/0000-0001-8318-2513

${ }^{2}$ Universidad de las Fuerzas Armadas. (ESPE), Carrera: Pedagogía de la Actividad Física y Deporte correo cegonzalez7@espe.edu.ec ORCID ID https://orcid.org/0000-0002-3130-8644

${ }^{3}$ Universidad de las Fuerzas Armadas. (ESPE), Carrera: Pedagogía de la Actividad Física y Deporte correo mlsandoval1@espe.edu.ec ORCID ID: https://orcid.org/0000-0003-1532-1862
} 
16-year-old students and finally 18-year-old students, in conclusion it can be mentioned that, in the Theodore Wilbur Anderson Educational Unit, students belonging to Basic Higher Education that oscillate between 16,17, 18 years are the most active and more interested in the subject of physical recreation in free time.

Keywords: Physical recreation, free time, Recreational activities

\section{Resumen}

El presente artículo se basa en la recreación física junto con el tiempo libre de los estudiantes de Educación Básica Superior de la Unidad Educativa Theodore Wilbur Anderson para poder conocer el uso que le dan a su tiempo libre, y así también saber si en dicho tiempo realizan o conocen sobre la recreación física, debido a que en esta época de clases en línea muchos adolescentes han dado más tiempo y uso a los aparatos electrónicos, lo que ha ocasionado un descuidado en realizar actividades físicas en el poco o mucho tiempo libre que disponen, es por eso que el objetivo general en este estudio es analizar el uso adecuado del tiempo libre de los estudiantes con el fin de proponer una planificación basada en lo que es la recreación física para que los estudiantes aprovechen de mejor manera su tiempo libre, por lo cual, se realizó una extensa revisión teórica y bibliográfica de diversos autores, este estudio se llevó a cabo a través de una investigación descriptiva, para poder analizar los datos recopilados se empleó un cuestionario realizado en Google Forms con 7 preguntas los cuales dieron los siguientes resultados, los estudiantes de 17 años de la Unidad Educativa Theodore Wilbur Anderson son los más interesados en realizar actividades físicas en su tiempo libre, en segundo lugar están los estudiantes de 16 años y por último los estudiantes de 18 años, en conclusión se puede mencionar que, en la Unidad Educativa Theodore Wilbur Anderson los estudiantes pertenecientes a la Educación Superior Básica que oscila entre los 16,17, 18 años son las personas más activas y más interesadas por el tema de la recreación física en el tiempo libre.

Palabras claves: Recreación física, tiempo libre, actividades recreativas.

\section{Introducción}

Durante la pandemia del COVID-19, la población ha tomado medidas de bioseguridad para prevenir la propagación del virus, a través del distanciamiento social e higiene personal. Pero se ha olvidado una parte importante que es la recreación física y sus múltiples beneficios en su tiempo libre, ya que por las medidas adoptadas se han visto obligados a mantenerse frente al computador o aparatos tecnológicos por largo tiempo, teniendo inconvenientes en la salud como el sedentarismo, obesidad, estrés, entre otros.

"Todos los niños y adolescentes deben practicar una actividad física de intensidad moderada o alta durante un mínimo de 60 minutos diarios, al menos 3 días por semana, esto debe incluir actividades que fortalezcan los músculos y huesos, hacer ejercicio durante más de 60 minutos diarios aporta beneficios adicionales para la salud" (OMS, 2021, pp.1). 
Por otra parte, la mejor manera de contrarrestar el sedentarismo en la actualidad es con la realización de la termogénesis no asociada al ejercicio, en la cual muestra diversas maneras de mantenerse activo mejorando el estilo de vida de las personas. (Pedraza, 2018)

La situación actual también ha resaltado la importancia que tiene la actividad física y recreativa para disminuir las complicaciones del contagio pues las personas cuidan de su salud física, mental y emocional. Por tal motivo los jóvenes obtienen más beneficios al realizar dichas acciones como lo son la reducción de ansiedad y depresión aumentando los niveles de energía puesto que motivan a la realización de actividades recreacionales con la familia y su entorno (García, 2019). Por ello, debería impartirse en las clases virtuales la importancia de realizar estas actividades, para incentivar al trabajo de rutinas básicas, juegos y actividades, con los cuales se dé hincapié a la motivación de los jóvenes en mantener un estilo de vida activo, eliminando hábitos no saludables de su vida diaria.

"A pesar de los cambios causados por la pandemia de la COVID-19 aún es posible divertirnos. En realidad, identificar actividades divertidas quizás ahora sea aún más importante. Hacer algo que disfrutas puede distraerte de los problemas y ayudarte a afrontar los desafíos que presenta la vida" (Anónimo, 2020, pp.1).

Las actividades de recreación física son esenciales para la población en especial de los estudiantes adolescentes, durante y después de las actividades cotidianas con el propósito de utilizar de manera óptima y adecuada el tiempo libre.

"Toda actividad física es beneficiosa y puede realizarse como parte del trabajo, el deporte y el ocio o el transporte (caminar, patinar y montar en bicicleta), pero también del baile, el juego y las tareas domésticas cotidianas, como la jardinería y la limpieza" (OMS, 2021, pp.1).

Cabe señalar que la sociedad ha perdido la práctica de actividades recreativas, ya sea por falta de información o falta de interés de la sociedad y eso no ayuda a abrir un panorama claro de la importancia de dichas actividades en la vida de los seres humanos, pues bien, se conoce que existe un bajo porcentaje de personas que dan importancia a la realización de actividad física entendiéndolo como apoyo para su desarrollo integral.

La mayoría de los estudiantes que cursan niveles superiores suelen descuidar la actividad física, porque se ven involucrados en utilizar ese tiempo libre en ejecutar otras actividades como juegos en línea, exceso de redes sociales, abuso de actividades multimedia, etc. Sin embargo, los adolescentes suelen afirmar erróneamente que disfrutan de la realización de dichas acciones en su tiempo de ocio ya que son productivas para su desarrollo intelectual y físico. (Krech, s.f., como se citó en la OMS, 2021) afirma que, la duración del ejercicio o cualquier actividad física, beneficia a la salud haciendo referencia a que si te mueves más es mejor, así lo mencionó dicho Director de Promoción de la salud de la Organización Mundial de la Salud, aparte de permanecer tras un computador por largos periodos, es por ello que se debe incentivar al aprovechamiento de tiempo libre de forma adecuada para combatir con los efectos nocivos del sedentarismo. 
Esta investigación juega un papel fundamental para los seres humanos puesto que, cuando llegan a su etapa de adolescencia se mantienen de manera aislada además de querer convivir en un mundo tecnológico apartado de la sociedad en la que se encuentra, es decir fuera de su realidad. Por consiguiente, los jóvenes dejan de lado el compartir con las demás personas de su alrededor, y de realizar actividades recreativas las cuales brindan beneficios y mejoran las habilidades cognitivas, sociales, motrices y emocionales. De esta manera aprenden a relacionarse con sus semejantes, además ayudan a potencializar sus capacidades manteniendo confianza entre ellos mismos dejando de lado el aislamiento que conlleva el uso excesivo de aparatos electrónicos.

"La recreación es una actividad integral, un fenómeno general, constituido por formas creativas específicas que se expresan en actividades artísticas, literarias, cognoscitivas, físico-deportivas, educativas y profilácticas, sin olvidar algunas formas particulares que presentan la suma o integración de más de un grupo de actividades señaladas, por ello está estrechamente relacionado con la educación, autoeducación, higiene física y psíquica, la cultura y la diversión, que cumplen un papel coadyuvante en la formación de la personalidad en el socialismo, además planteaba que la recreación posee tal potencial en Cuba que demuestra que ningún país en el mundo puede desarrollar tanta recreación sana y a través de esta elevar la calidad de vida y la cultura general integral de nuestra población, a pesar de lo cual existen insuficiencias en la instrumentación de programas capaces de satisfacer estas expectativas" (Font, 2014, pp.1).

Esta revisión busca analizar los factores predisponentes que tienen los jóvenes al no realizar actividad física recreativa por la cultura que se mantiene a nivel del país, debido a que no dan la importancia y el beneficio que estas actividades. Además, pueden lograr una calidad de vida adecuada a su edad, es por ello que se ha tomado en cuenta a la "Unidad Educativa Particular Theodore Wilbur Anderson" junto con la colaboración de un grupo de adolescentes de segundo de bachillerato para valorar el tiempo que emplean para realizar actividad física recreativa.

\section{Actividad Física}

La actividad física hace referencia al movimiento corporal que realiza el ser humano lo cual representa un consumo de energía adicional para mantener sus funciones vitales de una manera estable, es decir, utiliza dicha energía para realizar actividades de la vida diaria ya sean estas caminar, correr, trasladar objetos de un lugar a otro, subir o bajar escaleras y demás. Perea et. al (2019). Es importante realizar de manera rutinaria dichas actividades para que el cuerpo cree un balance energético del movimiento manteniéndose activo y con más vitalidad.

\section{Recreación Física}

La recreación es un factor esencial para tener una calidad de vida adecuada dejando de lado los malos hábitos como el sedentarismo, ya que mediante el mismo se logran desarrollar varias habilidades físicas que fortalecen al ser humano en un proceso de 
mejora. Por lo cual, la recreación física contribuye a dicho proceso tanto social como mental, de tal forma si es bien encaminado el desarrollo educativo puede contribuir a potencializar las actividades sanas y alegres de una manera pedagógica.

"Las actividades físicas recreativas al concebir un conjunto de actividades de diversos tipos y ser ejecutada en el tiempo libre, brinda al individuo la satisfacción por su realización, la misma representa para el niño un medio a través del cual contribuye a su desarrollo físico, social e intelectual; para el joven la acción, la aventura, la independencia y para el adulto un elemento higiénico y de descanso activo." (Avilés, 2010, pp.1)

Es decir que, la recreación física aporta a una vida integral combatiendo la inactividad a nivel mundial siendo una de las principales causas de muerte, y es por ello la importancia de contribuir a la motivación en dichas actividades, además obtiene múltiples beneficios ya que varias investigaciones demuestran que se aprende mucho más en ambientes tranquilos y acogedores. (Zapata, 2016)

Cabe destacar que la recreación física combate varias causas que peligra la salud integral de la persona, es por ello que, hay variedad de actividades recreativas de acuerdo al interés de cada persona, por esa misma razón se los debe dejar que actúen de forma espontánea sin poner reglas, metas o exigencias y sensibilizar su parte creativa, imaginativa aparte buscar una relajación al realizar este tipo de actividades. (Díaz, 2020)

\section{Tiempo Libre}

Es un periodo fuera de lo habitual en el cual se dispone a realizar actividades fuera de las obligaciones cotidianas, entre las acciones que se pueden dedicar las personas a ejecutar son el tiempo a la diversión y al descanso. Principalmente este tiempo sirve para liberar preocupaciones, estrés, cambios de ánimo y socializar de mejor manera.

"El Tiempo Libre a aquel tiempo que la gente le dedica a aquellas actividades que no corresponden a su trabajo formal ni a tareas domésticas esenciales. Su rasgo diferencial es que se trata de un tiempo recreativo el cual puede ser utilizado por "su titular" a discreción, es decir, a diferencia de lo que ocurre con aquel tiempo no libre en el cual la mayoría de las veces no se puede elegir el tiempo de realización, en este, la persona puede decidir cuántas horas destinarle.” (Agila, 2016, pp.8)

Es por ello que, este tiempo principalmente se tiene principalmente después de haber realizado las labores, deberes, tareas y cualquier tipo de responsabilidad que ya sea impuesta, por esa misma razón es que ayuda al cuerpo a relajarse, distraerse y desarrollar de forma armónica un ambiente de tranquilidad. (Montes, Gómez, 2014)

El tiempo libre no se debería verse como algo positivo o negativo, debido a que hay actividades para aprovechar dichos espacios en la rutina habitual, es importante resaltar que las actividades realizadas no siempre tienen un buen aprovechamiento por parte de 
las personas debido a que las nuevas formas de vida han evolucionado y ya no son las mismas necesidades que se requiere en la actualidad. (Sánchez, Jurado, Simoes, 2013)

\section{Beneficios de la Recreación Física en el tiempo libre}

La recreación física en el tiempo libre es un pilar fundamental para promover la salud por tal motivo se obtiene varios beneficios, como los más importantes tenemos:

1. Adecuada Movilidad articular

2. Fortalecimiento de Grupo Musculares

3. Prevención de lesiones

4. Prevención de enfermedades no transmisibles (ENT)

El ser humano por su naturaleza, desarrolla habilidades de acuerdo al medio donde se forma, mismas que se reflejan a múltiples condiciones por esa misma razón es que la salud es de suma importancia a la hora de realizar recreación física en el tiempo libre. Los beneficios más notorios a la hora de hablar de estas actividades son: controlar nuestro factor de ira, aumenta el trabajo en equipo, mantiene un peso adecuado a su IMC. (Puente, Sandoval, Medina, Estrada, 2011)

\section{Metodología}

Se realizó una investigación cuantitativa debido a que el objetivo es corroborar el tiempo libre de los estudiantes de la "Unidad Educativa Theodore Wilbur Anderson", además de desarrollar una investigación de análisis descriptivo debido a que se basó en algunos estudios para poder comprobar y analizar nuestros resultados.

La investigación se caracteriza por ser de alcance descriptiva, según Peña (2012) afirma que: "También conocida como la investigación estadística, se describen los datos y características de la población o fenómeno en estudio. Este nivel de Investigación responde a las preguntas: quién, qué, dónde, cuándo y cómo"

Para conocer qué actividades realizan dichos estudiantes en el tiempo libre, el instrumento para la recopilación de datos fue la encuesta que ayudó a determinar las variables de recreación física y tiempo libre para ello se elaboró un cuestionario basado en siete preguntas, todo acorde a lo que es el tiempo libre y la recreación física que disponen los estudiantes, cabe señalar que todas las preguntas fueron de respuestas cerradas. Es importante resaltar que la encuesta aplicada a los estudiantes fue aprobada y revisada por un experto, el cual tuvo como objetivo analizar el nivel de actividad física que emplean en el tiempo libre los adolescentes.

\section{Muestra}

La investigación tiene como participantes a los estudiantes que se encuentran cursando el nivel de segundo de bachillerato de la Unidad Educativa Theodore Wilbur Anderson, ubicado en la provincia de Pichincha del cantón Quito. Es decir, el número total de participantes $n=(38)$. 
Todos los estudiantes que cursan la Educación Básica Superior de la Unidad Educativa Theodore Wilbur Anderson fueron encuestados mediante la plataforma de Microsoft Teams que tuvo una duración de 30 minutos.

La tabulación y análisis de datos fue elaborado en el programa SPSS con el Software IBM SPSS Statistics 21. La interpretación de los resultados dio hincapié a la elaboración de las conclusiones y recomendaciones.

\section{Resultados y discusión}

Tabla 1. Edad y Género

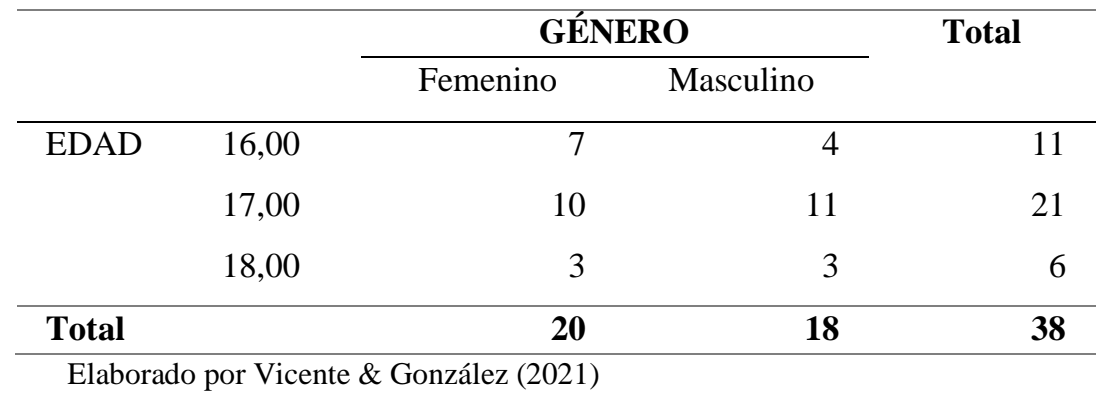

Se observa que, de los 38 participantes de esta investigación, 20 participantes son de género femenino y 18 son de género masculino de los cuales 7 mujeres y 4 hombres están en la edad de 16 años, mientras que 10 mujeres y 11 hombres están en la edad de 17 años, así 3 mujeres y 3 hombres están en la edad de 18 años, los mismos que participan del cuestionario Google Formulario con el tema La recreación física en el tiempo libre de los estudiantes de educación básica superior.

\section{Tabla de frecuencia}

Tabla 2 P1. ¿Cuántas horas diarias tienes de promedio fuera de tus obligaciones (escuela, tareas, ayuda en casa, entrenamientos deportivos, transporte, necesidades fisiológicas)

\begin{tabular}{|c|c|c|c|c|c|c|}
\hline & & & & \multicolumn{2}{|c|}{ GÉNERO } & \multirow[t]{2}{*}{ Total } \\
\hline & & & & Femenino & Masculino & \\
\hline \multirow{6}{*}{$\begin{array}{l}\text { De } 0 \text { a } 1 \\
\text { hora }\end{array}$} & EDAD & 17,00 & Recuento & 1 & 3 & 4 \\
\hline & & & $\begin{array}{l}\text { \% dentro de } \\
\text { GÉNERO }\end{array}$ & $100,0 \%$ & $75,0 \%$ & $80,0 \%$ \\
\hline & & 18,00 & Recuento & 0 & 1 & 1 \\
\hline & & & $\begin{array}{l}\% \text { dentro de } \\
\text { GÉNERO }\end{array}$ & $0,0 \%$ & $25,0 \%$ & $20,0 \%$ \\
\hline & & & Recuento & 1 & 4 & 5 \\
\hline & & & $\begin{array}{l}\text { \% dentro de } \\
\text { GÉNERO }\end{array}$ & $100,0 \%$ & $100,0 \%$ & $100,0 \%$ \\
\hline \multirow{3}{*}{$\begin{array}{l}\text { De } 1 \text { a } 2 \\
\text { horas }\end{array}$} & EDAD & 16,00 & Recuento & 1 & 1 & 2 \\
\hline & & & $\begin{array}{l}\% \text { dentro de } \\
\text { GÉNERO }\end{array}$ & $11,1 \%$ & $20,0 \%$ & $14,3 \%$ \\
\hline & & 17,00 & Recuento & 7 & 3 & 10 \\
\hline
\end{tabular}


Tabla 2 P1. ¿Cuántas horas diarias tienes de promedio fuera de tus obligaciones (escuela, tareas, ayuda en casa, entrenamientos deportivos, transporte, necesidades fisiológicas) (continuación)

\begin{tabular}{|c|c|c|c|c|c|c|}
\hline & & & & \multicolumn{2}{|c|}{ GÉNERO } & \multirow[t]{2}{*}{ Total } \\
\hline & & & & Femenino & Femenino & \\
\hline \multirow[t]{5}{*}{ De 1 a 2 horas } & & & $\begin{array}{l}\text { \% dentro de } \\
\text { GÉNERO }\end{array}$ & $77,8 \%$ & $60,0 \%$ & $71,4 \%$ \\
\hline & & 18,00 & Recuento & 1 & 1 & 2 \\
\hline & & & $\begin{array}{l}\% \text { dentro de } \\
\text { GÉNERO }\end{array}$ & $11,1 \%$ & $20,0 \%$ & $14,3 \%$ \\
\hline & & & Recuento & 9 & 5 & 14 \\
\hline & & & $\begin{array}{c}\% \text { dentro de } \\
\text { GÉNERO }\end{array}$ & $100,0 \%$ & $100,0 \%$ & $100,0 \%$ \\
\hline \multirow{6}{*}{$\begin{array}{l}\text { De } 3 \text { a } 4 \\
\text { horas }\end{array}$} & EDAD & 16,00 & Recuento & 3 & 1 & 4 \\
\hline & & & $\begin{array}{c}\% \text { dentro de } \\
\text { GÉNERO }\end{array}$ & $100,0 \%$ & $20,0 \%$ & $50,0 \%$ \\
\hline & & 17,00 & Recuento & 0 & 4 & 4 \\
\hline & & & $\begin{array}{c}\% \text { dentro de } \\
\text { GÉNERO }\end{array}$ & $0,0 \%$ & $80,0 \%$ & $50,0 \%$ \\
\hline & & & Recuento & 3 & 5 & 8 \\
\hline & & & $\begin{array}{c}\% \text { dentro de } \\
\text { GÉNERO }\end{array}$ & $100,0 \%$ & $100,0 \%$ & $100,0 \%$ \\
\hline \multirow{8}{*}{$\begin{array}{l}\text { De } 5 \text { a } 6 \\
\text { horas }\end{array}$} & EDAD & 16,00 & Recuento & 3 & 1 & 4 \\
\hline & & & $\begin{array}{c}\% \text { dentro de } \\
\text { GÉNERO }\end{array}$ & $75,0 \%$ & $33,3 \%$ & $57,1 \%$ \\
\hline & & 17,00 & Recuento & 0 & 1 & 1 \\
\hline & & & $\begin{array}{c}\% \text { dentro de } \\
\text { GÉNERO }\end{array}$ & $0,0 \%$ & $33,3 \%$ & $14,3 \%$ \\
\hline & & 18,00 & Recuento & 1 & 1 & 2 \\
\hline & & & $\begin{array}{c}\% \text { dentro de } \\
\text { GÉNERO }\end{array}$ & $25,0 \%$ & $33,3 \%$ & $28,6 \%$ \\
\hline & & & Recuento & 4 & 3 & 7 \\
\hline & & & $\begin{array}{l}\% \text { dentro de } \\
\text { GÉNERO }\end{array}$ & $100,0 \%$ & $100,0 \%$ & $100,0 \%$ \\
\hline \multirow{4}{*}{$\begin{array}{l}\text { De } 7 \text { a } 8 \\
\text { horas }\end{array}$} & EDAD & 17,00 & Recuento & 1 & & 1 \\
\hline & & & $\begin{array}{c}\% \text { dentro de } \\
\text { GÉNERO }\end{array}$ & $100,0 \%$ & & $100,0 \%$ \\
\hline & & & Recuento & 1 & & 1 \\
\hline & & & $\begin{array}{c}\% \text { dentro de } \\
\text { GÉNERO }\end{array}$ & $100,0 \%$ & & $100,0 \%$ \\
\hline \multirow{5}{*}{$\begin{array}{l}\text { Más de } 8 \\
\text { hora }\end{array}$} & EDAD & 16,00 & Recuento & 0 & 1 & 1 \\
\hline & & & $\begin{array}{c}\% \text { dentro de } \\
\text { GÉNERO }\end{array}$ & $0,0 \%$ & $100,0 \%$ & $33,3 \%$ \\
\hline & & 17,00 & Recuento & 1 & 0 & 1 \\
\hline & & & $\begin{array}{c}\% \text { dentro de } \\
\text { GÉNERO }\end{array}$ & $50,0 \%$ & $0,0 \%$ & $33,3 \%$ \\
\hline & & 18,00 & Recuento & 1 & 0 & 1 \\
\hline
\end{tabular}


Tabla 2 P1. ¿Cuántas horas diarias tienes de promedio fuera de tus obligaciones (escuela, tareas, ayuda en casa, entrenamientos deportivos, transporte, necesidades fisiológicas) (continuación)

\begin{tabular}{|c|c|c|c|c|c|c|}
\hline & & & & \multicolumn{2}{|c|}{ GÉNERO } & \multirow[t]{2}{*}{ Total } \\
\hline & & & & Femenino & Femenino & \\
\hline & & & $\begin{array}{l}\% \text { dentro de } \\
\text { GÉNERO }\end{array}$ & $50,0 \%$ & $0,0 \%$ & $33,3 \%$ \\
\hline & & Total & Recuento & 2 & 1 & 3 \\
\hline & & & $\begin{array}{l}\% \text { dentro de } \\
\text { GÉNERO }\end{array}$ & $100,0 \%$ & $100,0 \%$ & $100,0 \%$ \\
\hline \multirow[t]{8}{*}{ Total } & EDAD & 16,00 & Recuento & 7 & 4 & 11 \\
\hline & & & $\begin{array}{l}\% \text { dentro de } \\
\text { GÉNERO }\end{array}$ & $35,0 \%$ & $22,2 \%$ & $28,9 \%$ \\
\hline & & 17,00 & Recuento & 10 & 11 & 21 \\
\hline & & & $\begin{array}{l}\% \text { dentro de } \\
\text { GÉNERO }\end{array}$ & $50,0 \%$ & $61,1 \%$ & $55,3 \%$ \\
\hline & & 18,00 & Recuento & 3 & 3 & 6 \\
\hline & & & $\begin{array}{l}\% \text { dentro de } \\
\text { GÉNERO }\end{array}$ & $15,0 \%$ & $16,7 \%$ & $15,8 \%$ \\
\hline & \multirow{2}{*}{\multicolumn{2}{|c|}{ Total }} & Recuento & 20 & 18 & 38 \\
\hline & & & $\begin{array}{l}\text { \% dentro de } \\
\text { GÉNERO }\end{array}$ & $100,0 \%$ & $100,0 \%$ & $100,0 \%$ \\
\hline
\end{tabular}

Elaborado por Vicente \& González (2021)

Se observa en la P1 ¿Cuántas horas diarias tienen de promedio fuera de tus obligaciones (escuela, tareas, ayuda en casa, entrenamientos deportivos, transporte, necesidades fisiológicas) en relación a las opciones determinadas como también en dependencia a la edad y género encontramos los siguientes resultados significativos; es así como en la opción de $\mathbf{0}$ a 1 hora encontramos que en el género masculino se obtiene 3 participantes en la edad de 17 años equivaliendo al 75\% de participación con mayor incidencia; en la opción de 1 a 2 horas se observa que en la edad de 17 años a el género femenino se encuentra 7 integrantes los mismos que equivalen al 77,8\% de frecuencia mientras que en el género masculino 3 participantes lo que equivale a un $60 \%$ de frecuencia en esta respuesta; en la opción de $\mathbf{3}$ a 4 horas observamos que en la edad de 16 años en el género femenino estos 3 participantes los que equivale al 100\% de la respuesta, mientras que en los varones se encuentra 4 participantes que equivale al $80 \%$ de las respuestas en esta opción; en la opción de 5 a 6 horas encontramos con mayor relevancia en la edad de 16 años del género femenino con 3 participantes lo que equivale al $75 \%$ siendo el dato más significativo; en la opción de 7 a 8 horas encontramos con mayor significancia en las edades de 17 en el género femenino 1 participación; así también en la opción más de 8 horas con 1 participación con edades de 17 a 18 años así en el género masculino 1 respuesta favorable en la edad de 16 años. Se observa que los jóvenes de género masculino de la edad de 17 años son los que mayor cantidad de horas promedio tienen, seguidos de las mujeres de 17 años que tienen una frecuencia de 10 participantes de la totalidad de 38 entre los diferentes años, los jóvenes de género femenino de la edad de 16 
años son los que tienen 7 horas promedio lo que representa el $35 \%$ de la totalidad de los diferentes años, así como también los jóvenes de género masculino y femenino de 18 años son los que menos cantidad de horas promedio tienen en la totalidades de resultados.

Una vez analizado los resultados obtenidos en la P1 de la encuesta, se observa que los jóvenes de 17 años tiene de promedio entre 1 a 2 horas con mayor frecuencia y le sigue la opción de 3 a 4 horas que tienen de promedio los jóvenes de 16 años en el caso de las mujeres y 17 años en el caso de los varones, las mujeres de 16 años son las que más horas promedio de 5 a 6 en relación a los varones; los varones entre las edades de 17 años son los que menos horas promedio tienen siendo de 0 a 1 hora.

Tabla 2. P2. ¿A qué actividades dedicas la mayor parte de tu tiempo libre?

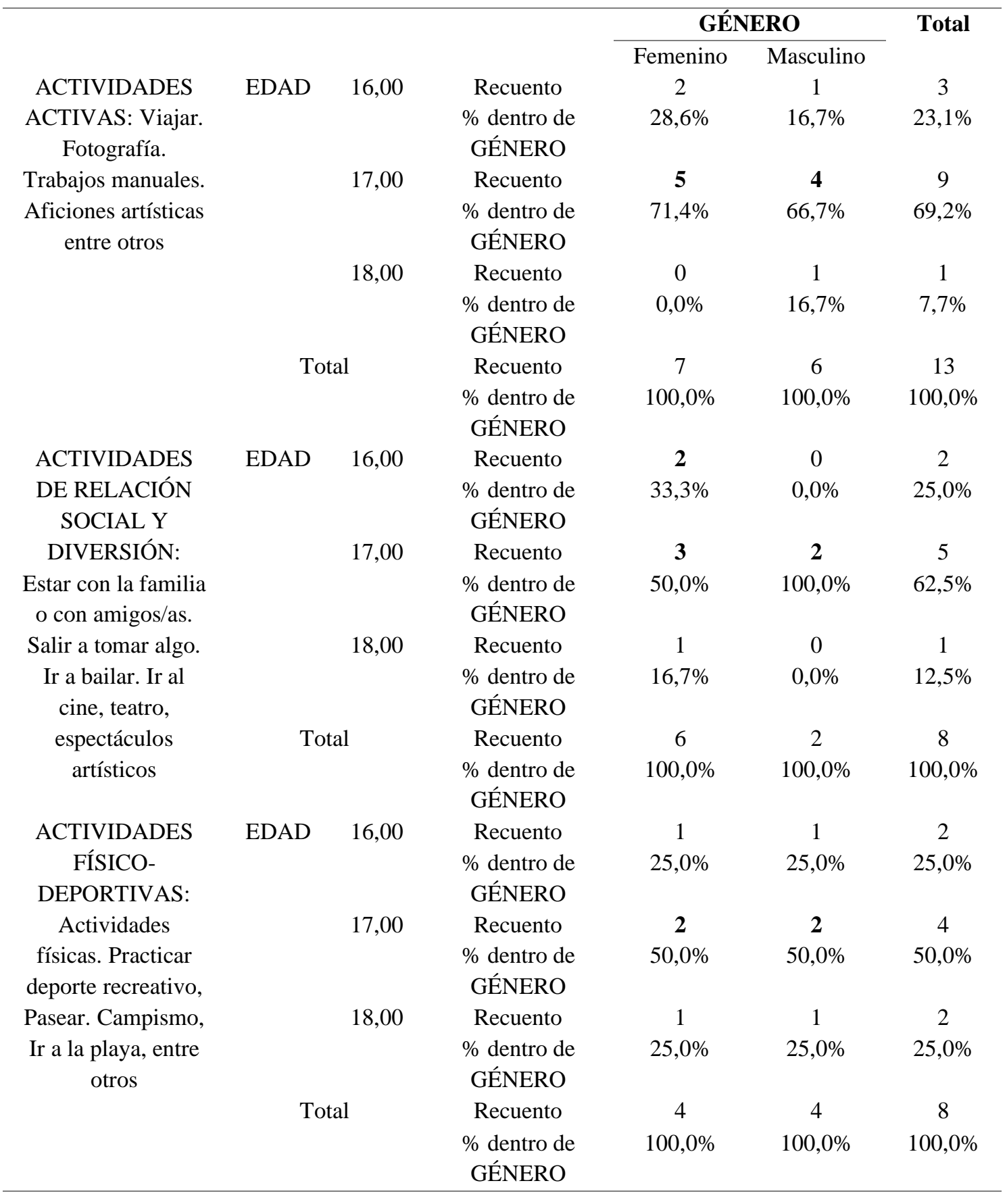


Tabla 2. P2. ¿A qué actividades dedicas la mayor parte de tu tiempo libre?

\begin{tabular}{|c|c|c|c|c|c|c|}
\hline \multirow[b]{3}{*}{ ACTIVIDADES } & & & & \multicolumn{2}{|c|}{ GÉNERO } & \multirow[t]{2}{*}{ Total } \\
\hline & & & & Femenino & Masculino & \\
\hline & EDAD & 16,00 & Recuento & 2 & 2 & 4 \\
\hline $\begin{array}{l}\text { PASIVAS: Juegos } \\
\text { en línea, }\end{array}$ & & & $\begin{array}{l}\% \text { dentro de } \\
\text { GÉNERO }\end{array}$ & $66,7 \%$ & $33,3 \%$ & $44,4 \%$ \\
\hline videojuegos, Ver & & 17,00 & Recuento & 0 & 3 & 3 \\
\hline $\begin{array}{l}\text { T.V o videos. } \\
\text { Escribir, Escuchar }\end{array}$ & & & $\begin{array}{l}\% \text { dentro de } \\
\text { GÉNERO }\end{array}$ & $0,0 \%$ & $50,0 \%$ & $33,3 \%$ \\
\hline $\begin{array}{l}\text { radio. Leer libros, } \\
\text { periódicos, } \\
\text { revistas. Sin hacer }\end{array}$ & & 18,00 & $\begin{array}{l}\text { Recuento } \\
\% \text { dentro de } \\
\text { GÉNERO }\end{array}$ & $\begin{array}{c}1 \\
33,3 \%\end{array}$ & $\begin{array}{c}1 \\
16,7 \%\end{array}$ & $\begin{array}{c}2 \\
22,2 \%\end{array}$ \\
\hline nada en particular & & & $\begin{array}{l}\text { Recuento } \\
\% \text { dentro de } \\
\text { GÉNERO }\end{array}$ & $\begin{array}{c}3 \\
100,0 \%\end{array}$ & $\begin{array}{c}6 \\
100,0 \%\end{array}$ & $\begin{array}{c}9 \\
100,0 \%\end{array}$ \\
\hline \multirow[t]{4}{*}{ Total } & EDAD & 16,00 & $\begin{array}{l}\text { Recuento } \\
\% \text { dentro de } \\
\text { GÉNERO }\end{array}$ & $\begin{array}{c}7 \\
35,0 \%\end{array}$ & $\begin{array}{c}4 \\
22,2 \%\end{array}$ & $\begin{array}{c}11 \\
28,9 \%\end{array}$ \\
\hline & & 17,00 & $\begin{array}{l}\text { Recuento } \\
\% \text { dentro de } \\
\text { GÉNERO }\end{array}$ & $\begin{array}{c}10 \\
50,0 \%\end{array}$ & $\begin{array}{c}11 \\
61,1 \%\end{array}$ & $\begin{array}{c}21 \\
55,3 \%\end{array}$ \\
\hline & & 18,00 & $\begin{array}{l}\text { Recuento } \\
\% \text { dentro de } \\
\text { GÉNERO }\end{array}$ & $\begin{array}{c}3 \\
15,0 \%\end{array}$ & $\begin{array}{c}3 \\
16,7 \%\end{array}$ & $\begin{array}{c}6 \\
15,8 \%\end{array}$ \\
\hline & \multicolumn{2}{|c|}{ Total } & $\begin{array}{l}\text { Recuento } \\
\text { \% dentro de } \\
\text { GÉNERO }\end{array}$ & $\begin{array}{c}20 \\
100,0 \%\end{array}$ & $\begin{array}{c}18 \\
\mathbf{1 0 0 , 0} \%\end{array}$ & $\begin{array}{c}38 \\
100,0 \%\end{array}$ \\
\hline
\end{tabular}

Elaborado por Vicente \& González (2021)

Se observa en la P2 ¿A qué actividades dedicas la mayor parte de tu tiempo libre? En relación a las opciones determinadas como también en dependencia a la edad y género encontramos los siguientes resultados significativos en cada una de ellas; en la opción de ACTIVIDADES ACTIVAS: Viajar. Fotografía. Trabajos manuales. Aficiones artísticas entre otros encontramos que en el género femenino tiene 5 participantes en la edad de 17 años con el 71,4\% y en el género masculino en la edad de 17 años tiene 4 participantes con el 66,7\% confirmando que la mujercitas en esta edad tiene preferencia por actividades activas mayor que los jóvenes varones como también los jóvenes de 16 como de 18 años no tiene mayor preferencia en esta actividad; en la opción de ACTIVIDADES DE RELACIÓN SOCIAL Y DIVERSIÓN: Estar con la familia o con amigos/as. Salir a tomar algo. Ir a bailar. Ir al cine, teatro, espectáculos artísticos encontramos que las jóvenes de 16 y 17 años son las que tienen mayor preferencia por esta actividad de relación social mientras que en los jóvenes de género masculino de 17 años tiene preferencia por estas actividades en relación a los jóvenes hombre de 16 y 17 años; en la alternativa ACTIVIDADES FÍSICO-DEPORTIVAS: Actividades físicas. Practicar deporte recreativo, Pasear. Campismo, Ir a la playa, entre otros; encontramos que tanto los jóvenes de género masculino y femenino en la edad de 17 años son los que mayor preferencia tienen en relación a los jóvenes tanto hombre como mujeres de la edad de 16 y 18 años; en la opción ACTIVIDADES PASIVAS: Juegos en línea, 
videojuegos, Ver T.V o videos. Escribir, Escuchar radio. Leer libros, periódicos, revistas. Sin hacer nada en particular; Se observa que los jóvenes de género femenino y masculino en la edad de 16 años tiene preferencia por dedicarse a esta actividad y así con mayor frecuencia los de género masculino que tiene la edad de 17 años determinando que los jóvenes de 18 años tanto hombres como mujeres tiene muy poco interés en estas actividades

Los adolescentes prefieren más las actividades activas debido a que

Tabla 3 P3. Te interesas la actividad físico-recreativa

\begin{tabular}{|c|c|c|c|c|c|c|}
\hline & & & & \multicolumn{2}{|c|}{ GÉNERO } & \multirow[t]{2}{*}{ Total } \\
\hline & & & & Femenino & Masculino & \\
\hline \multirow[t]{8}{*}{ Bastante } & EDAD & 16,00 & Recuento & 2 & 2 & 4 \\
\hline & & & $\%$ dentro de GÉNERO & $28,6 \%$ & $25,0 \%$ & $26,7 \%$ \\
\hline & & 17,00 & Recuento & 4 & 5 & 9 \\
\hline & & & $\%$ dentro de GÉNERO & $57,1 \%$ & $62,5 \%$ & $60,0 \%$ \\
\hline & & 18,00 & Recuento & 1 & 1 & 2 \\
\hline & & & $\%$ dentro de GÉNERO & $14,3 \%$ & $12,5 \%$ & $13,3 \%$ \\
\hline & & & Recuento & 7 & 8 & 15 \\
\hline & & & $\%$ dentro de GÉNERO & $100,0 \%$ & $100,0 \%$ & $100,0 \%$ \\
\hline \multirow[t]{8}{*}{ Mucho } & EDAD & 16,00 & & 1 & 1 & 2 \\
\hline & & & $\%$ dentro de GÉNERO & $16,7 \%$ & $12,5 \%$ & $14,3 \%$ \\
\hline & & 17,00 & Recuento & 4 & 5 & 9 \\
\hline & & & $\%$ dentro de GÉNERO & $66,7 \%$ & $62,5 \%$ & $64,3 \%$ \\
\hline & & 18,00 & Recuento & 1 & 2 & 3 \\
\hline & & & $\%$ dentro de GÉNERO & $16,7 \%$ & $25,0 \%$ & $21,4 \%$ \\
\hline & & & Recuento & 6 & 8 & 14 \\
\hline & & & $\%$ dentro de GÉNERO & $100,0 \%$ & $100,0 \%$ & $100,0 \%$ \\
\hline \multirow[t]{8}{*}{ Poco } & EDAD & 16,00 & Recuento & 4 & 1 & 2 \\
\hline & & & $\%$ dentro de GÉNERO & $57,1 \%$ & $50,0 \%$ & $55,6 \%$ \\
\hline & & 17,00 & Recuento & 2 & 1 & 3 \\
\hline & & & $\%$ dentro de GÉNERO & $28,6 \%$ & $50,0 \%$ & $33,3 \%$ \\
\hline & & 18,00 & Recuento & 1 & 0 & 4 \\
\hline & & & $\%$ dentro de GÉNERO & $14,3 \%$ & $0,0 \%$ & $11,1 \%$ \\
\hline & \multicolumn{2}{|c|}{ Total } & Recuento & 7 & 2 & 9 \\
\hline & & & $\%$ dentro de GÉNERO & $100,0 \%$ & $100,0 \%$ & $100,0 \%$ \\
\hline Total & EDAD & 16,00 & Recuento & 7 & 4 & 11 \\
\hline
\end{tabular}


Tabla 3 P3. Te interesas la actividad físico-recreativa (continuación)

\begin{tabular}{|c|c|c|c|c|}
\hline & & \multicolumn{2}{|c|}{ GÉNERO } & \multirow[t]{2}{*}{ Total } \\
\hline & & Femenino & Femenino & \\
\hline & $\%$ dentro de GÉNERO & $35,0 \%$ & $22,2 \%$ & $28,9 \%$ \\
\hline \multirow[t]{2}{*}{17,00} & Recuento & 10 & 11 & 21 \\
\hline & $\%$ dentro de GÉNERO & $50,0 \%$ & $61,1 \%$ & $55,3 \%$ \\
\hline \multirow{4}{*}{ Total } & Recuento & 3 & 3 & 6 \\
\hline & $\%$ dentro de GÉNERO & $15,0 \%$ & $16,7 \%$ & $15,8 \%$ \\
\hline & Recuento & 20 & 18 & 38 \\
\hline & $\begin{array}{l}\text { \% dentro de } \\
\text { GÉNERO }\end{array}$ & $100,0 \%$ & $100,0 \%$ & $100,0 \%$ \\
\hline
\end{tabular}

Elaborado por Vicente \& González (2021)

Se observa en la P3 ¿Te interesas la actividad físico-recreativa? en relación a las opciones determinadas como también en dependencia a la edad y género encontramos los siguientes resultados significativos en cada una de ellas; en la opción de Bastante interés encontramos que a los jóvenes de género femenino y masculino de 17 años son los que más les interesa seguido de los jóvenes de 16 años tanto hombres como mujeres a los jóvenes de 18 años no tiene mayor interés en las actividades físico -recreativos en la valoración de Mucho interés en las actividad físico-recreativa encontramos que los jóvenes tanto hombres como mujeres son los que tiene mayor frecuencia en esta respuesta y en la valoración de Poco interés en las actividades físicas recreativas encontramos que los jóvenes de género femenino en la edad de 16 años son los que mayor frecuencia tiene lo que determina que poco interés tienen en las actividades físico -recreativas

Tabla 4. P4. ¿Cuántas horas dedicas a la semana a la práctica de actividad física recreativa?

\begin{tabular}{|c|c|c|c|c|c|c|}
\hline & & & & GÉ & RO & Total \\
\hline & & & & Femenino & Masculino & \\
\hline \multirow[t]{8}{*}{1 hora o menos } & EDAD & 16,00 & Recuento & 4 & 1 & 5 \\
\hline & & & $\begin{array}{c}\% \text { dentro de } \\
\text { GÉNERO }\end{array}$ & $44,4 \%$ & $33,3 \%$ & $41,7 \%$ \\
\hline & & 17,00 & Recuento & 5 & 1 & 6 \\
\hline & & & $\begin{array}{c}\% \text { dentro de } \\
\text { GÉNERO }\end{array}$ & $55,6 \%$ & $33,3 \%$ & $50,0 \%$ \\
\hline & & 18,00 & Recuento & 0 & 1 & 1 \\
\hline & & & $\begin{array}{c}\text { \% dentro de } \\
\text { GÉNERO }\end{array}$ & $0,0 \%$ & $33,3 \%$ & $8,3 \%$ \\
\hline & & Total & Recuento & 9 & 3 & 12 \\
\hline & & & $\begin{array}{c}\text { \% dentro de } \\
\text { GÉNERO }\end{array}$ & $100,0 \%$ & $100,0 \%$ & $100,0 \%$ \\
\hline \multirow[t]{3}{*}{ De 2 a 3 horas } & EDAD & 16,00 & Recuento & 2 & 1 & 3 \\
\hline & & & $\begin{array}{l}\% \text { dentro de } \\
\text { GÉNERO }\end{array}$ & $50,0 \%$ & $25,0 \%$ & $37,5 \%$ \\
\hline & & 17,00 & Recuento & 2 & 3 & 5 \\
\hline
\end{tabular}


Tabla 4. P4. ¿Cuántas horas dedicas a la semana a la práctica de actividad física recreativa? (continuación)

\begin{tabular}{|c|c|c|c|c|c|c|}
\hline & & & & \multicolumn{2}{|c|}{ GÉNERO } & \multirow[t]{2}{*}{ Total } \\
\hline & & & & Femenino & Femenino & \\
\hline & & & $\begin{array}{l}\text { \% dentro de } \\
\text { GÉNERO }\end{array}$ & $50,0 \%$ & $75,0 \%$ & $62,5 \%$ \\
\hline & & Total & Recuento & 4 & 4 & 8 \\
\hline & & & $\begin{array}{l}\% \text { dentro de } \\
\text { GÉNERO }\end{array}$ & $100,0 \%$ & $100,0 \%$ & $100,0 \%$ \\
\hline \multirow{8}{*}{ De 4 a 5 horas } & EDAD & 16,00 & Recuento & 1 & 0 & 1 \\
\hline & & & $\begin{array}{l}\% \text { dentro de } \\
\text { GÉNERO }\end{array}$ & $25,0 \%$ & $0,0 \%$ & $14,3 \%$ \\
\hline & & 17,00 & Recuento & 2 & 3 & 5 \\
\hline & & & $\begin{array}{l}\text { \% dentro de } \\
\text { GÉNERO }\end{array}$ & $50,0 \%$ & $100,0 \%$ & $71,4 \%$ \\
\hline & & 18,00 & Recuento & 1 & 0 & 1 \\
\hline & & & $\begin{array}{l}\text { \% dentro de } \\
\text { GÉNERO }\end{array}$ & $25,0 \%$ & $0,0 \%$ & $14,3 \%$ \\
\hline & & Total & Recuento & 4 & 3 & 7 \\
\hline & & & $\begin{array}{l}\% \text { dentro de } \\
\text { GÉNERO }\end{array}$ & $100,0 \%$ & $100,0 \%$ & $100,0 \%$ \\
\hline \multirow[t]{8}{*}{ Más de 6 hora } & EDAD & 16,00 & Recuento & 0 & 2 & 2 \\
\hline & & & $\begin{array}{l}\% \text { dentro de } \\
\text { GÉNERO }\end{array}$ & $0,0 \%$ & $25,0 \%$ & $18,2 \%$ \\
\hline & & 17,00 & Recuento & 1 & 4 & 5 \\
\hline & & & $\begin{array}{l}\% \text { dentro de } \\
\text { GÉNERO }\end{array}$ & $33,3 \%$ & $50,0 \%$ & $45,5 \%$ \\
\hline & & 18,00 & Recuento & 2 & 2 & 4 \\
\hline & & & $\begin{array}{l}\text { \% dentro de } \\
\text { GÉNERO }\end{array}$ & $66,7 \%$ & $25,0 \%$ & $36,4 \%$ \\
\hline & & Total & Recuento & 3 & 8 & 11 \\
\hline & & & $\begin{array}{l}\% \text { dentro de } \\
\text { GÉNERO }\end{array}$ & $100,0 \%$ & $100,0 \%$ & $100,0 \%$ \\
\hline \multirow[t]{8}{*}{ Total } & EDAD & 16,00 & Recuento & 7 & 4 & 11 \\
\hline & & & $\begin{array}{l}\% \text { dentro de } \\
\text { GÉNERO }\end{array}$ & $35,0 \%$ & $22,2 \%$ & $28,9 \%$ \\
\hline & & 17,00 & Recuento & 10 & 11 & 21 \\
\hline & & & $\begin{array}{l}\% \text { dentro de } \\
\text { GÉNERO }\end{array}$ & $50,0 \%$ & $61,1 \%$ & $55,3 \%$ \\
\hline & & 18,00 & Recuento & 3 & 3 & 6 \\
\hline & & & $\begin{array}{l}\text { \% dentro de } \\
\text { GÉNERO }\end{array}$ & $15,0 \%$ & $16,7 \%$ & $15,8 \%$ \\
\hline & & Total & Recuento & 20 & 18 & 38 \\
\hline & & & $\begin{array}{l}\text { \% dentro de } \\
\text { GÉNERO }\end{array}$ & $100,0 \%$ & $100,0 \%$ & $100,0 \%$ \\
\hline
\end{tabular}

Elaborado por Vicente \& González (2021)

Se observa en la P4 ¿Cuántas horas dedicas a la semana a la práctica de actividad física recreativa? en relación a las opciones determinadas como también en dependencia a la edad y género encontramos los siguientes resultados significativos en cada una de ellas; en la opción de en 1 hora o menos encontramos que a los jóvenes de género femenino 
son los que mayor frecuencia tienen tanto en las jóvenes de 16 y 17 años en la opción de 2 a 3 horas y en el caso de los varones en la edad de 17 años son las que dedican de 2 a 3 horas con mayor frecuencia en sus resultados, en la opción de $\mathbf{4}$ a 5 horas se observa que tanto mujeres como varones en la edad de 17 años son los que mayor frecuencia tienen; así también los jóvenes que dedican más de 6 horas a la semana a la práctica de actividades físicas recreativas son los de género masculino que tienen 17 años con un porcentaje del 50\% en relación a los de 16 y 18 años, en esta carga horaria podemos observar que de igual forma los jóvenes tanto masculinos como femeninos tienen una frecuencia en esta carga horaria teniendo las mujeres en un 66,7\% en relación a las otras edades y los varones en un 25\%, concluyendo que las mujeres en edades de 17 años son las que mayor cantidad de horas dedican a la semana para las actividades físicas recreativas y detrás las mujeres de 16 años y por último las mujercitas de 18 años de edad mientras que en los varones de 17 años son los que dedicas mayor tiempo a la semana para las actividades físicas recreativas seguidos de los jóvenes varones de 16 años y posteriormente los que tienen 18 años.

Tabla 5. P5. ¿Te gustaría hacer actividad física recreativa en tu tiempo libre?

\begin{tabular}{|c|c|c|c|c|c|c|}
\hline & & & & \multicolumn{2}{|c|}{ GÉNERO } & \multirow[t]{2}{*}{ Total } \\
\hline & & & & Femenino & Masculino & \\
\hline & \multirow[t]{2}{*}{ EDAD } & 17,00 & Recuento & 1 & & 1 \\
\hline & & & \% dentro de GÉNERO & $100,0 \%$ & & $100,0 \%$ \\
\hline & \multirow{2}{*}{\multicolumn{2}{|c|}{ Total }} & Recuento & 1 & & 1 \\
\hline & & & \% dentro de GÉNERO & $100,0 \%$ & & $100,0 \%$ \\
\hline \multirow[t]{6}{*}{ NO } & EDAD & 16,00 & Recuento & 1 & 1 & 2 \\
\hline & & & $\%$ dentro de GÉNERO & $50,0 \%$ & $50,0 \%$ & $50,0 \%$ \\
\hline & & 17,00 & Recuento & 1 & 1 & 2 \\
\hline & & & \% dentro de GÉNERO & $50,0 \%$ & $50,0 \%$ & $50,0 \%$ \\
\hline & & & Recuento & 2 & 2 & 4 \\
\hline & & & $\%$ dentro de GÉNERO & $100,0 \%$ & $100,0 \%$ & $100,0 \%$ \\
\hline \multirow[t]{8}{*}{ SI } & EDAD & 16,00 & Recuento & 6 & 3 & 9 \\
\hline & & & \% dentro de GÉNERO & $35,3 \%$ & $18,8 \%$ & $27,3 \%$ \\
\hline & & 17,00 & Recuento & 8 & 10 & 18 \\
\hline & & & $\%$ dentro de GÉNERO & $47,1 \%$ & $62,5 \%$ & $54,5 \%$ \\
\hline & & 18,00 & Recuento & 3 & 3 & 6 \\
\hline & & & \% dentro de GÉNERO & $17,6 \%$ & $18,8 \%$ & $18,2 \%$ \\
\hline & \multirow{2}{*}{\multicolumn{2}{|c|}{ Total }} & Recuento & 17 & 16 & 33 \\
\hline & & & \% dentro de GÉNERO & $100,0 \%$ & $100,0 \%$ & $100,0 \%$ \\
\hline
\end{tabular}


Tabla 5. P5. ¿Te gustaría hacer actividad física recreativa en tu tiempo libre? (continuación)

\begin{tabular}{|c|c|c|c|c|c|c|}
\hline & & & & \multicolumn{2}{|c|}{ GÉNERO } & \multirow[t]{2}{*}{ Total } \\
\hline & & & & Femenino & Femenino & \\
\hline \multirow[t]{8}{*}{ Total } & EDAD & 16,00 & Recuento & 7 & 4 & 11 \\
\hline & & & \% dentro de GÉNERO & $35,0 \%$ & $22,2 \%$ & $28,9 \%$ \\
\hline & & 17,00 & Recuento & 10 & 11 & 21 \\
\hline & & & \% dentro de GÉNERO & $50,0 \%$ & $61,1 \%$ & $55,3 \%$ \\
\hline & & 18,00 & Recuento & 3 & 3 & 6 \\
\hline & & & \% dentro de GÉNERO & $15,0 \%$ & $16,7 \%$ & $15,8 \%$ \\
\hline & \multirow{2}{*}{\multicolumn{2}{|c|}{ Total }} & Recuento & 20 & 18 & 38 \\
\hline & & & \% dentro de GÉNERO & $100,0 \%$ & $100,0 \%$ & $100,0 \%$ \\
\hline
\end{tabular}

Elaborado por Vicente \& González (2021)

Se observa en la P5 ¿Te gustaría hacer actividad física recreativa en tu tiempo libre? en relación a las opciones determinadas como también en dependencia a la edad y género encontramos los siguientes resultados significativos en cada una de ellas; se observa que tanto los jóvenes de género masculino como femenino tiene un agrado por realizar actividades recreativas en el tiempo libre pero mayormente los jóvenes de 17 años son los que tienen el interés por esta práctica y menor interés los jóvenes mujeres y hombres de 18 años, como también tienen menor porcentaje de interés los jóvenes hombres de 16 y 18 años.

Tabla 6 P6. ¿Qué modalidades de actividad físicas y recreativas te gustaría realizar en tu tiempo libre en días laborables?

\begin{tabular}{|c|c|c|c|c|c|c|}
\hline & & & & \multicolumn{2}{|c|}{ GÉNERO } & \multirow[t]{2}{*}{ Total } \\
\hline & & & & Femenino & Masculino & \\
\hline \multirow{8}{*}{$\begin{array}{l}\text { Actividad física de } \\
\text { mantenimiento, } \\
\text { por gusto y salud } \\
\text { como gimnasio, } \\
\text { nadar, ciclear, } \\
\text { nadar, correr, entre } \\
\text { otro }\end{array}$} & \multirow[t]{6}{*}{ EDAD } & \multirow[t]{2}{*}{16,00} & Recuento & 2 & 2 & 4 \\
\hline & & & $\begin{array}{l}\% \text { dentro de } \\
\text { GÉNERO }\end{array}$ & $50,0 \%$ & $28,6 \%$ & $36,4 \%$ \\
\hline & & \multirow[t]{2}{*}{17,00} & Recuento & 1 & 4 & 5 \\
\hline & & & $\begin{array}{c}\% \text { dentro de } \\
\text { GÉNERO }\end{array}$ & $25,0 \%$ & $57,1 \%$ & $45,5 \%$ \\
\hline & & \multirow[t]{2}{*}{18,00} & Recuento & 1 & 1 & 2 \\
\hline & & & $\begin{array}{l}\% \text { dentro de } \\
\text { GÉNERO }\end{array}$ & $25,0 \%$ & $14,3 \%$ & $18,2 \%$ \\
\hline & \multirow{2}{*}{\multicolumn{2}{|c|}{ Total }} & Recuento & 4 & 7 & 11 \\
\hline & & & $\begin{array}{l}\% \text { dentro de } \\
\text { GÉNERO }\end{array}$ & $100,0 \%$ & $100,0 \%$ & $100,0 \%$ \\
\hline \multirow{5}{*}{$\begin{array}{l}\text { Actividades } \\
\text { acruvas como } \\
\text { pasear, caminar, } \\
\text { jugar con amigos o } \\
\text { familiares, bailar. }\end{array}$} & \multirow[t]{5}{*}{ EDAD } & 16,00 & Recuento & 2 & 0 & 2 \\
\hline & & & $\begin{array}{c}\% \text { dentro de } \\
\text { GÉNERO }\end{array}$ & $33,3 \%$ & $0,0 \%$ & $22,2 \%$ \\
\hline & & 17,00 & Recuento & 4 & 2 & 6 \\
\hline & & & $\begin{array}{l}\% \text { dentro de } \\
\text { GÉNERO }\end{array}$ & $66,7 \%$ & $66,7 \%$ & $66,7 \%$ \\
\hline & & 18,00 & Recuento & 0 & 1 & 1 \\
\hline
\end{tabular}


Tabla 6 P6. ¿Qué modalidades de actividad físicas y recreativas te gustaría realizar en tu tiempo libre en días laborables? (continuación)

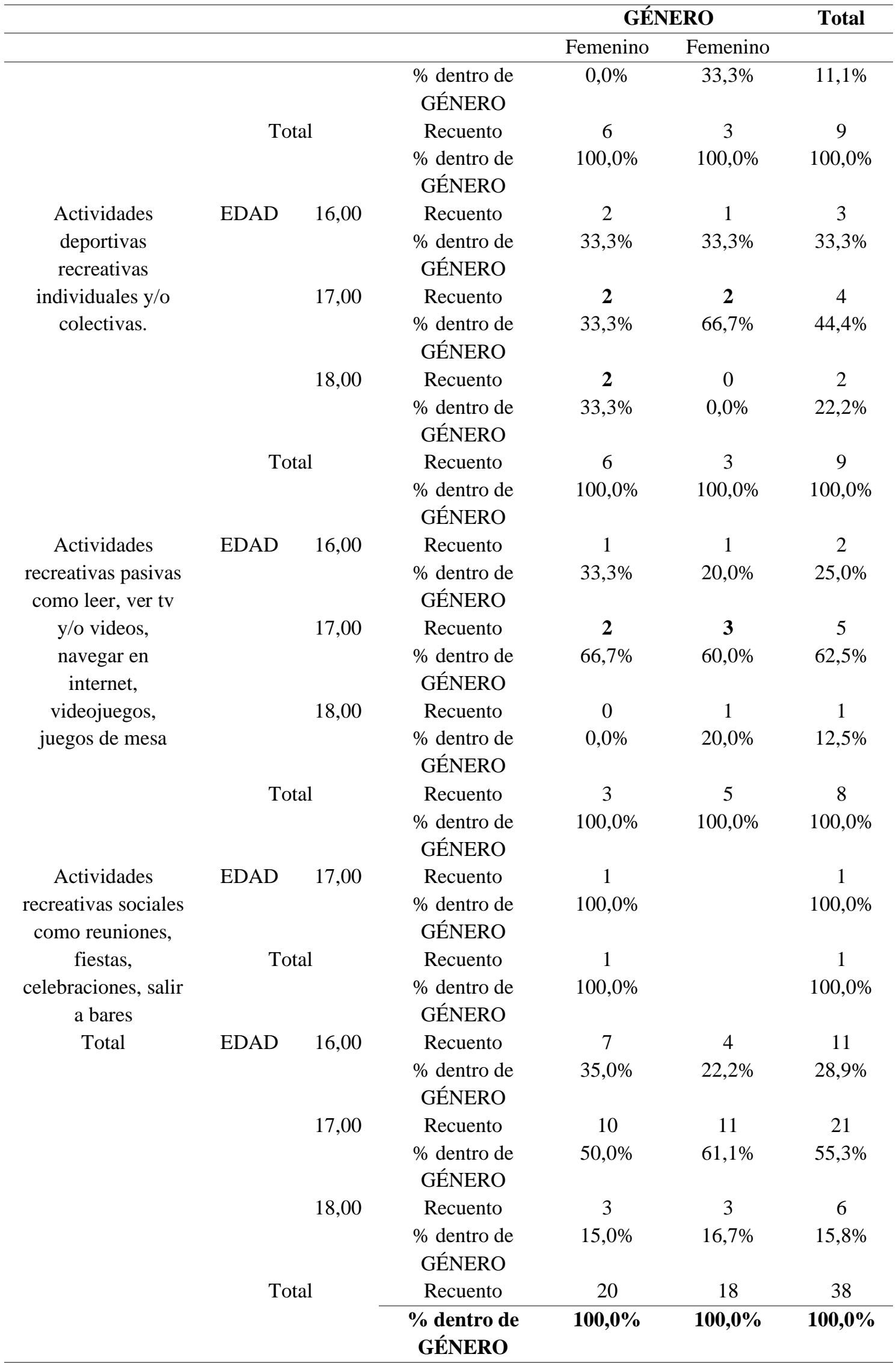


Se observa en la P6 ¿Qué modalidades de actividad físicas y recreativas te gustaría realizar en tu tiempo libre en días laborales? en la opción de actividad física de mantenimiento, por gusto y salud como gimnasio, nadar, ciclear, nadar, correr, entre otro, observamos que los jóvenes de género masculino en la edad de 17 años prefieren las actividades de mantenimiento, seguido de los jóvenes tanto hombres como mujeres de 16 años, no ha si los jóvenes hombres y mujeres de 18 años quienes no tienen interés por actividades físicas de mantenimiento; en la opción Actividades acruvas como pasear, caminar, jugar con amigos o familiares, bailar, se observa que los jóvenes de género femenino de 17 años tienen mayor preferencia por esta actividad seguidos por las mujeres de 16 años y jóvenes hombres de 17 años en menor proporción; en la opción de Actividades deportivas recreativas individuales y/o colectivas. Observamos que las mujeres de 16, 17 y 18 años tienen una preferencia en realizar actividades recreativas individuales y colectivas como también en la misma proporción los jóvenes hombres de 17 años; en la opción Actividades recreativas pasivas como leer, ver tv y/o videos, navegar en internet, videojuegos, juegos de mesa, se observa que los jóvenes de 17 años tanto hombres como mujeres prefieren este tipo de actividades; así podemos encontrar en la última opción que es Actividades recreativas sociales como reuniones, fiestas, celebraciones, salir a bares; encontramos que las mujeres de 17 años tienen porcentaje bajo en esta opción.

Tabla 7 P7. ¿Qué modalidades de actividad físicas y recreativas te gustaría realizar en tu tiempo libre en fin de semana?

\begin{tabular}{|c|c|c|c|c|c|c|}
\hline & & & & GÉ & RO & Total \\
\hline & & & & Femenino & Masculino & \\
\hline Actividad física de & EDAD & 16,00 & Recuento & 2 & 2 & 4 \\
\hline $\begin{array}{l}\text { mantenimiento, } \\
\text { por gusto y salud }\end{array}$ & & & $\begin{array}{l}\% \text { dentro de } \\
\text { GÉNERO }\end{array}$ & $33,3 \%$ & $50,0 \%$ & $40,0 \%$ \\
\hline como gimnasio, & & 17,00 & Recuento & 3 & 1 & 4 \\
\hline $\begin{array}{c}\text { nadar, ciclear, } \\
\text { nadar, correr, entre }\end{array}$ & & & $\begin{array}{c}\% \text { dentro de } \\
\text { GÉNERO }\end{array}$ & $50,0 \%$ & $25,0 \%$ & $40,0 \%$ \\
\hline otro & & 18,00 & Recuento & 1 & 1 & 2 \\
\hline & & & $\begin{array}{l}\text { \% dentro de } \\
\text { GÉNERO }\end{array}$ & $16,7 \%$ & $25,0 \%$ & $20,0 \%$ \\
\hline & & & Recuento & 6 & 4 & 10 \\
\hline & & & $\begin{array}{c}\text { \% dentro de } \\
\text { GÉNERO }\end{array}$ & $100,0 \%$ & $100,0 \%$ & $100,0 \%$ \\
\hline Actividades & EDAD & 16,00 & Recuento & 1 & 1 & 2 \\
\hline $\begin{array}{c}\text { acruvas como } \\
\text { pasear, caminar, }\end{array}$ & & & $\begin{array}{l}\% \text { dentro de } \\
\text { GÉNERO }\end{array}$ & $33,3 \%$ & $25,0 \%$ & $28,6 \%$ \\
\hline jugar con amigos o & & 17,00 & Recuento & 2 & 3 & 5 \\
\hline familiares, bailar. & & & $\begin{array}{c}\% \text { dentro de } \\
\text { GÉNERO }\end{array}$ & $66,7 \%$ & $75,0 \%$ & $71,4 \%$ \\
\hline & & & Recuento & 3 & 4 & 7 \\
\hline & & & $\begin{array}{c}\% \text { dentro de } \\
\text { GÉNERO }\end{array}$ & $100,0 \%$ & $100,0 \%$ & $100,0 \%$ \\
\hline
\end{tabular}


Tabla 7 P7. ¿Qué modalidades de actividad físicas y recreativas te gustaría realizar en tu tiempo libre en fin de semana? (continuación)

\begin{tabular}{|c|c|c|c|c|c|c|}
\hline & & & & \multicolumn{2}{|c|}{ GÉNERO } & \multirow[t]{2}{*}{ Total } \\
\hline \multirow{4}{*}{$\begin{array}{l}\text { Actividades } \\
\text { deportivas } \\
\text { recreativas }\end{array}$} & & & & Femenino & Femenino & \\
\hline & \multirow[t]{7}{*}{ EDAD } & 16,00 & Recuento & 1 & 0 & 1 \\
\hline & & & $\%$ dentro de & $25,0 \%$ & $0,0 \%$ & $16,7 \%$ \\
\hline & & & GÉNERO & & & \\
\hline \multirow{6}{*}{$\begin{array}{c}\text { individuales y/o } \\
\text { colectivas. }\end{array}$} & & 17,00 & Recuento & 2 & 1 & 3 \\
\hline & & & $\begin{array}{l}\% \text { dentro de } \\
\text { GÉNERO }\end{array}$ & $50,0 \%$ & $50,0 \%$ & $50,0 \%$ \\
\hline & & 18,00 & Recuento & 1 & 1 & 2 \\
\hline & & & $\begin{array}{l}\% \text { dentro de } \\
\text { GÉNERO }\end{array}$ & $25,0 \%$ & $50,0 \%$ & $33,3 \%$ \\
\hline & \multirow{2}{*}{\multicolumn{2}{|c|}{ Total }} & Recuento & 4 & 2 & 6 \\
\hline & & & $\begin{array}{l}\text { \% dentro de } \\
\text { GÉNERO }\end{array}$ & $100,0 \%$ & $100,0 \%$ & $100,0 \%$ \\
\hline \multirow{8}{*}{$\begin{array}{c}\text { Actividades } \\
\text { recreativas pasivas } \\
\text { como leer, ver tv } \\
\text { y/o videos, navegar } \\
\text { en internet, } \\
\text { videojuegos, } \\
\text { juegos de mesa }\end{array}$} & \multirow[t]{8}{*}{ EDAD } & \multirow[t]{2}{*}{16,00} & Recuento & 2 & 1 & 3 \\
\hline & & & $\begin{array}{l}\% \text { dentro de } \\
\text { GÉNERO }\end{array}$ & $40,0 \%$ & $20,0 \%$ & $30,0 \%$ \\
\hline & & \multirow[t]{2}{*}{17,00} & Recuento & 2 & 3 & 5 \\
\hline & & & $\begin{array}{l}\% \text { dentro de } \\
\text { GÉNERO }\end{array}$ & $40,0 \%$ & $60,0 \%$ & $50,0 \%$ \\
\hline & & \multirow[t]{2}{*}{18,00} & Recuento & 1 & 1 & 2 \\
\hline & & & $\begin{array}{l}\% \text { dentro de } \\
\text { GÉNERO }\end{array}$ & $20,0 \%$ & $20,0 \%$ & $20,0 \%$ \\
\hline & & \multirow[t]{2}{*}{ otal } & Recuento & 5 & 5 & 10 \\
\hline & & & $\begin{array}{l}\% \text { dentro de } \\
\text { GÉNERO }\end{array}$ & $100,0 \%$ & $100,0 \%$ & $100,0 \%$ \\
\hline \multirow{6}{*}{$\begin{array}{c}\text { Actividades } \\
\text { recreativas sociales } \\
\text { como reuniones, } \\
\text { fiestas, } \\
\text { celebraciones, salir } \\
\text { a bares }\end{array}$} & \multirow[t]{4}{*}{ EDAD } & \multirow[t]{2}{*}{16,00} & Recuento & 1 & 0 & 1 \\
\hline & & & $\begin{array}{l}\text { \% dentro de } \\
\text { GÉNERO }\end{array}$ & $50,0 \%$ & $0,0 \%$ & $20,0 \%$ \\
\hline & & \multirow[t]{2}{*}{17,00} & Recuento & 1 & 3 & 4 \\
\hline & & & $\begin{array}{l}\% \text { dentro de } \\
\text { GÉNERO }\end{array}$ & $50,0 \%$ & $100,0 \%$ & $80,0 \%$ \\
\hline & \multirow{2}{*}{\multicolumn{2}{|c|}{ Total }} & Recuento & 2 & 3 & 5 \\
\hline & & & $\begin{array}{l}\% \text { dentro de } \\
\text { GÉNERO }\end{array}$ & $100,0 \%$ & $100,0 \%$ & $100,0 \%$ \\
\hline \multirow[t]{8}{*}{ Total } & \multirow[t]{6}{*}{ EDAD } & \multirow[t]{2}{*}{16,00} & Recuento & 7 & 4 & 11 \\
\hline & & & $\begin{array}{l}\% \text { dentro de } \\
\text { GÉNERO }\end{array}$ & $35,0 \%$ & $22,2 \%$ & $28,9 \%$ \\
\hline & & \multirow[t]{2}{*}{17,00} & Recuento & 10 & 11 & 21 \\
\hline & & & $\begin{array}{l}\% \text { dentro de } \\
\text { GÉNERO }\end{array}$ & $50,0 \%$ & $61,1 \%$ & $55,3 \%$ \\
\hline & & \multirow[t]{2}{*}{18,00} & Recuento & 3 & 3 & 6 \\
\hline & & & $\begin{array}{l}\% \text { dentro de } \\
\text { GÉNERO }\end{array}$ & $15,0 \%$ & $16,7 \%$ & $15,8 \%$ \\
\hline & \multirow{2}{*}{\multicolumn{2}{|c|}{ Total }} & Recuento & 20 & 18 & 38 \\
\hline & & & $\begin{array}{l}\text { \% dentro de } \\
\text { GÉNERO }\end{array}$ & $100,0 \%$ & $100,0 \%$ & $100,0 \%$ \\
\hline
\end{tabular}


Se observa en la P7 ¿Qué modalidades de actividad físicas y recreativas te gustaría realizar en tu tiempo libre en fin de semana? en la opción de Actividad física de mantenimiento, por gusto y salud como gimnasio, nadar, ciclear, nadar, correr, entre otro, observamos que los jóvenes de género femenino de 17 años tienen mayor preferencia, seguidos de los jóvenes hombre y mujeres de 16 años; en la opción de Actividades acruvas como pasear, caminar, jugar con amigos o familiares, bailar; encontramos que los jóvenes de 17 años tanto mujeres como hombres tienen preferencia por esta condición de modalidad de actividad recreativa; en la opción de Actividades deportivas recreativas individuales y/o colectivas; se observa que las mujeres de 17 años tienen una mayor preferencia por esta opción mientras que es la opción de Actividades recreativas pasivas como leer, ver tv y/o videos, navegar en internet, videojuegos, juegos de mesa; se observa que los jóvenes de 17 años y mayormente los varones prefieren este tipo de actividades seguidos de la mujeres de esta misma edad así con la última opción Actividades recreativas sociales como reuniones, fiestas, celebraciones, salir a bares; donde se observa que los que mayor preferencia tienen son los varones de 17 años los mismo que tienen mayor proporción y frecuencia en esta opción.

Los resultados finales de la encuesta aplicada a los estudiantes que cursan la Educación Básica Superior de la "Unidad Educativa Theodore Wilbur Anderson", que oscilan entre 16 a 18 años, los estudiantes de 17 años son las personas están más interesadas en realizar recreación física en su tiempo libre debido a los resultados de la pregunta 5 qué es "¿te gustaría hacer actividad física en tu tiempo libre?” y 7 “¿Qué modalidades de actividad físicas y recreativas te gustaría realizar en tu tiempo libre en fin de semana?", en la mayoría los varones de esta edad son los más interesados y dispuestos están en realizar recreación física, seguido por las mujeres de su misma edad.

Los estudiantes de 16 años son aquellos que ocupan un segundo lugar pues están dispuestos hacer recreación física, además de realizar alguna actividad física en su tiempo libre, finalmente están los estudiantes de 18 años debido a que en esta muestra de 38 estudiantes tan solo dos personas pertenecen a esta lista etaria es por ello que los resultados no son tan alentadores para esta edad.

Con la propuesta se pretende hacer que todos los estudiantes de 16 a 18 años se motiven e interesen por realizar la recreación física en su tiempo libre, debido a que los resultados para estas edades no son favorables, es así que el propósito deseado es que todos los estudiantes se sensibilicen y comprendan la relevancia de realizar actividad física dejando de lado la utilización de aparatos tecnológicos.

\section{Propuesta}

En base a los estudios y resultados obtenidos en esta investigación, hemos decidido plantear una propuesta con el fin que en la "Unidad Educativa Particular Theodore Wilbur Anderson" específicamente los estudiantes de la educación básica superior que oscilan entre los 16 a los 18 años, consiste en que 3 veces al día realicen actividades físico 
recreativas por los menos 30 min horas clase, para ellos solo damos una pequeña guía con actividades físico recreativas que se pueden realizar.

Por otro lado, en esta propuesta se dará un solo juego por cada actividad establecida anteriormente que podrá ser variada dependiendo del o los responsables de poner en práctica dichas actividades.

La propuesta está establecida en los siguientes puntos:

1. Deportes de Orientación. - Deportes que se basan en el tiempo con la ayuda de un mapa o una brújula.

2. Competencia (circuito). - Actividad establecida con dificultades a lo largo del recorrido

3. Deportes recreativos. -Son actividades físicas en las que el objetivo principal es entretener a los jugadores, proporcionando placer y diversión.

\section{Actividades}

\section{Deporte de Orientación}

Nombre de la actividad. - La palabra perdida

\section{Materiales.}

Mapas topográficos de la institución, banderines, conos, letras impresas, silbato, cronómetro

\section{Desarrollo de la actividad.}

Se le dará un mapa topográfico de las instalaciones del colegio donde estará señalado algunos puntos importantes donde deben ir a recoger una letra que al final de todo el circuito formarán una palabra que deberán entregar en el punto de partida. Esta actividad se realizará en parejas.

\section{Competencia (circuito)}

Nombre de la actividad. - Los ganadores

Materiales. - Cuerdas, ula ula, conos, silbato, cronómetro

\section{Desarrollo de la actividad.}

En este circuito consistirá de 3 etapas cada equipo consta con 3 participantes en la primera etapa el equipo deberá escoger un participante que realizará saltos de cuerda donde debe hacer 10 saltos sin parar, si se equivoca o se para más de dos veces, el equipo deberá escoger otro competidor y empezar de nuevo.

En la segunda etapa deberán realizar giros con el ula ula el competidor debe realizar 10 vueltas sin parar, si el competidor se le cae o se equivoca deberán escoger otro participante para que realice la prueba. 
Para la última etapa será una carrera de relevos donde los participantes deberán completar ser estratégicos para completar el circuito.

Adicional en la carrera de relevos el participante que culmine las vueltas del ula ula será el primero corredor hasta llegar a su compañero que estará ubicado más adelante, todos los participantes deberán participar en el circuito, y todo el equipo deberán realizar pasar dos veces el circuito para poder ganar.

\section{Deportes Recreativos}

Nombre de la actividad. - Fútbol araña

\section{Materiales. -}

balones, arcos o conos, indumentaria deportiva, en caso que el piso sea irregular se recomienda guantes de tela, silbato y cronómetro

\section{Desarrollo de la actividad.}

Es una variante del fútbol, pero esta vez para desplazarnos lo haremos en cuadrúpeda, pero en la posición supino es decir con la mirada para arriba, se realizarán 4 equipos de 5 personas, el equipo que logre 5 goles en la puerta contraria seguirá jugando mientras que el equipo perdedor será reemplazado por los demás equipos.

\section{Conclusiones}

- En los estudios seleccionados para el análisis se pudo evidenciar que el tiempo libre en los adolescentes de Segundo de Bachillerato de la "Unidad Educativa Particular Theodore Wilbur Anderson" es mal empleado por los resultados obtenidos en la encuesta, debido a que existe falta de información por parte de las autoridades que desconocen la importancia de realizar actividades física recreativas en la adolescencia, principalmente en su tiempo libre ya que ahora por la modalidad de clases virtuales los estudiantes se han vuelto sedentarios, por ende se ha masificado la inactividad física en la juventud. Por lo cual, conocer sobre actividades físico recreativas donde solo se aborda fundamentación teórica en las cuales no se identifica las necesidades o intereses de los estudiantes al momento de realizar planificaciones acordes a ellos, con la intención de brindar un mejor uso de su tiempo libre.

- La conclusión es que se da a conocer que los estudiantes de 17 años le dan mayor importancia a la recreación física en el uso del tiempo libre, como se puede evidenciar en los resultados de las tablas cruzadas, de igual manera se observan a los estudiantes de 16 años. Sin embargo, cabe mencionar que los jóvenes de 18 años no realizan recreación física en su tiempo libre debido a que dentro de sus jornadas no existe motivación por parte de su entorno, además esta última fase etaria nos aborda resultados negativos debido a que el número de estudiantes de esa edad son tan solo de 2 personas por ende es que los jóvenes de 18 años son los que menos intereses tienen. 
- Para finalizar y mediante un análisis exhaustivo de nuestros resultados se presenta la propuesta de realizar actividades físico recreativas las cuales aportan a una vida más saludable de los adolescentes, combatiendo a su rutina sedentaria de la mayoría de los encuestados dando paso a la importancia de las actividades dentro del tiempo libre. Las presente actividades están divididas de la siguiente manera: Deporte de orientación, Deporte recreativo y Competencia entre otras. Con el fin de que los estudiantes de 16 y 18 años tomen importancia de practicar actividades físico recreativas donde puedan acoplar a sus rutinas diarias.

\section{Referencias bibliográficas}

Agila, O., (2016). Empleo del tiempo libre, las actividades físicas y recreativas en los niños del barrio el calvario de la ciudad de Catacocha cantón paltas. Universidad nacional de Loja. Titulación 2016. Loja - Ecuador.

Anónimo. (2020). Actividades seguras al aire libre durante la pandemia de COVID-19. MAYO CLINIC.

Avilés, R., (2010). La actividad física recreativa, vía sana para el disfrute de la comunidad. EFDeportes Facultad de Cultura Física. Camagüey-Cuba.

Díaz, M., (2020). La importancia de la recreación en el aprendizaje y desarrollo de los niños. Ciudad del deporte. Ciudad Viña del Mar-Chile.

Font, O., (2014). La Recreación Física en la adolescencia escolar. EFDeportes. Facultad de Cultura Física. Cienfuegos-Cuba.

García, W., (2019). Sedentarismo en niños y adolescentes: Factor de riesgo en aumento. Revista Científica Mundo de la Investigación y el Conocimiento. Vol. 3. Guayaquil- Ecuador.

Montes, M., Gomez, E., (2014). Ocio, Recreación y Tiempo libre. Instituto Colombiano de Bienestar Familiar-ICBF. Colombia.

OMS. (2021). Campañas mundiales de salud pública de la OMS. Organización Mundial de la Salud.

OMS. (2020). Cada movimiento cuenta para mejorar la salud - dice la OMS. Comunicado de prensa. Organización Mundial de la Salud.

Pedraza, A., (2018). Sedentarismo, alarmante problema de Salud Pública y necesidad de incluirlo como riesgo laboral. Universidad Politécnica de Pachuca. Pachuca, Hidalgo- México.

Peña, M., (2012). Metodología de la investigación. Universidad nacional de educación enrique guzmán y valle programa de titulación 2012. Sesión 4. Lima- Perú 
Perea Caballero, A., López Navarrete, G., Perea Martínez A., Reyes Gómez U., Santiago Lagunes L., Ríos Gallardo P., Lara Campos A., González Valadez A., García Osorio V., Hernández López M., Solís Aguilar D., y de la Paz Morales C., (2019). Importancia de la Actividad Física. Revista Médico-Científica de la Secretaría de Salud Jalisco. Jalisco- México.

Puente, M., Sandoval, M., Medina, R., Estrada, C., (2011). Uso del tiempo libre en alumnos de Educación Secundaria. ArgenMex. Educación Física. Temas y posiciones. La Plata-Argentina.

Sánchez, L., Jurao, L., Simoes, M., (2013). Después Del Trabajo ¿Qué Significado Tiene El Ocio, El Tiempo Libre Y La

Salud? Scielo. Universidad Federal de Paraíba-Brasil.

Zapata, A., (2016). Actividades recreativas en el aprovechamiento del tiempo libre de los estudiantes de la Unidad Educativa 14 de julio del Cantón Latacunga. Diseño del proyecto de investigación o trabajo de graduación previo a la obtención del título de licenciado/a en Ciencias Humanas y de la Educación mención Cultura Física. Ambato- Ecuador. 


\section{PARA CITAR EL ARTÍCULO INDEXADO.}

Bryan Efrén, V. F., Carlos Eduardo, G. C., \& María Lorena, S. J. (2021). La Recreación física en el tiempo libre de los estudiantes de educación básica superior.

ConcienciaDigital,
https://doi.org/10.33262/concienciadigital.v4i3.1.1897

\section{Liencia}

El artículo que se publica es de exclusiva responsabilidad de los autores y no necesariamente reflejan el pensamiento de la Revista Conciencia Digital.

El artículo queda en propiedad de la revista y, por tanto, su publicación parcial y/o total en otro medio tiene que ser autorizado por el director de la Revista Conciencia Digital.

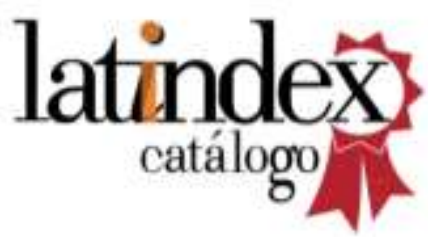

